\title{
Designing a 3D Printed Prosthetic to Meet Task-Specific Needs: A Case Study
}

\author{
Daniel Panchik \\ Elizabethtown College, panchikd@etown.edu
}

Gina C. Feeney

Elizabethtown College, feeneyg@etown.edu

Angeline A. Springer

Elizabethtown College, springera@etown.edu

Cristina G. VanBrocklin

Elizabethtown College, vanbrocklinc@etown.edu

Hannah E. Winters

Elizabethtown College, wintersh@etown.edu

Follow this and additional works at: https://nsuworks.nova.edu/ijahsp

Part of the Medicine and Health Sciences Commons

\section{Recommended Citation}

Panchik D, Feeney GC, Springer AA, VanBrocklin CG, Winters HE. Designing a 3D Printed Prosthetic to Meet Task-Specific Needs: A Case Study. The Internet Journal of Allied Health Sciences and Practice. 2021 Jan 01;19(2), Article 1.

This Case Study is brought to you for free and open access by the College of Health Care Sciences at NSUWorks. It has been accepted for inclusion in Internet Journal of Allied Health Sciences and Practice by an authorized editor of NSUWorks. For more information, please contact nsuworks@nova.edu. 


\title{
Designing a 3D Printed Prosthetic to Meet Task-Specific Needs: A Case Study
}

\begin{abstract}
The purpose of this case study is to explore the ease of utilizing task-specific design in computer-aided, open-source 3D printed design software. Two participants were recruited and assessed using subjective and objective measures to guide the prosthetic designs. Hand measurements were obtained and entered into computer software to create computer-aided design drawings of the digit prosthetics. Field notes were taken throughout this process by the interdisciplinary team and analyzed to address the ease of utilizing this technology. Objective assessments showed that both participants experienced decreased expansion, grip, and prehension strength of their affected hands. Semi-structured interviews with the participants identified several meaningful tasks that a prosthetic device could improve function in and offered valuable guidance in the development of the prosthetic designs. Analysis of the field notes allowed for the identification of six domains within the research questions. Those domains include appropriate assessment utilization, time management, participant responsiveness, clinical reasoning, common language, and available resources. The successful collaboration of occupational therapy (OT) and engineering disciplines resulted in customized 3D printed finger prosthetic designs to meet participants' specified tasks.
\end{abstract}

\section{Author Bio(s)}

Daniel Panchik, DSc., OTR/L, is a professor of Occupational Therapy at Elizabethtown College. He holds an MS degree in Occupational Therapy from the Medical College of Virginia, and a Doctor of Science in Occupational Therapy (Hand Rehabilitation) from Rocky Mountain University of Health Professions.

Gina C. Feeney, MS OTR/L., holds an MS degree in Occupational Therapy and a BS degree in Health and Occupation both from Elizabethtown College. Her undergraduate honor's thesis explored the continuum of care of individuals with peripheral vascular disease. At the time of this investigation, the author was completing her graduate studies.

Angeline A. Springer, MS., holds an MS degree in Occupational Therapy and a BS degree in Health and Occupation both from Elizabethtown College. At the time of this investigation, the author was completing her graduate studies.

Cristina G. VanBrocklin, MS OTR, holds an MS degree in Occupational Therapy and a BS degree in Health and Occupation both from Elizabethtown College. At the time of this investigation, the author was completing her graduate studies.

Hannah E. Winters, MS., holds an MS degree in Occupational Therapy and a BS degree in Health and Occupation both from Elizabethtown College. At the time of this investigation, the author was completing her graduate studies.

\section{Acknowledgements}

Significant credit goes to Dr. Kurt DeGeode and four students: Elle Shatto, Damon Edwards, Travis Wilson, and Robert Pavlik, who were completing their senior project in engineering. Particular recognition goes to Dr. Terri Dennehy for her faculty oversight. Finally, thank you to Mark Gatti for fabricating the BBT assessment tool's box and partition. 


\title{
IIAAHSP \\ The Internet Joumnal of Allied Health Sciences and Practice \\ Dedicated to allied health professional practice and education \\ Vol. 19 No. 2 ISSN 1540-580X
}

\section{Designing a 3D Printed Prosthetic to Meet Task-Specific Needs: A Case Study}

\author{
Daniel Panchik \\ Gina C. Feeney \\ Angeline A. Springer \\ Cristina G. VanBrocklin \\ Hannah E. Winters \\ Elizabethtown College \\ United States
}

\begin{abstract}
The purpose of this case study is to explore the ease of utilizing task-specific design in computer-aided, open-source 3D printed design software. Two participants were recruited and assessed using subjective and objective measures to guide the prosthetic designs. Hand measurements were obtained and entered into computer software to create computer-aided design drawings of the digit prosthetics. Field notes were taken throughout this process by the interdisciplinary team and analyzed to address the ease of utilizing this technology. Objective assessments showed that both participants experienced decreased expansion, grip, and prehension strength of their affected hands. Semi-structured interviews with the participants identified several meaningful tasks that a prosthetic device could improve function in and offered valuable guidance in the development of the prosthetic designs. Analysis of the field notes allowed for the identification of six domains within the research questions. Those domains include appropriate assessment utilization, time management, participant responsiveness, clinical reasoning, common language, and available resources. The successful collaboration of occupational therapy (OT) and engineering disciplines resulted in customized $3 \mathrm{D}$ printed finger prosthetic designs to meet participants' specified tasks.
\end{abstract}

KEYWORDS: 3D printing, 3D printed prosthetic design, finger amputation, computer-aided design, activity limitation. 


\section{INTRODUCTION}

The hand is a unique appendage that plays a vital role in how humans interact with their surrounding environment. People use their hands to participate in a myriad of meaningful activities and roles that shape their personal identities. However, the hand is also quite vulnerable, as it is only protected by a thin layer of fat and muscle and often comes in contact with potentially dangerous items in the environment. ${ }^{1}$ When the hand's functional abilities are impacted because of an amputation, the person's ability to participate in desired occupations is compromised. ${ }^{2}$

Limb loss due to amputations is predicted to increase significantly by the year 2050, reaching 3.6 million, as compared to 1.6 million in the year 2005.,3 Furthermore, the most common amputations seen in the United States are hand and partial-hand amputations. ${ }^{4}$ Current design and fabrication methods are lengthy, taking up to several weeks; in addition, they are costly because of the elaborate use of materials and increased expenditure for labor. 2,5 Prosthetic design and fabrication will need to adapt to meet the changing demands of this growing population. For example, one 2011 study found that almost $70 \%$ of upper limb prosthetic users were displeased with their prosthetic device's functioning while completing daily tasks. ${ }^{6}$ One small pilot study found customizing a 3D printed prosthetic to a specific task increases overall satisfaction with prosthetic use compared to costly commercially-produced prosthetics. ${ }^{7}$ Moreover, nearly $52 \%$ of those with upper limb amputations do not wear their prosthetics because it is neither functional nor aesthetically pleasing. ${ }^{8}$ However, upper extremity amputees tend to select their prosthetics based on its ability to meet their highly individualized, functional needs. ${ }^{9}$

Therapists working with the upper extremity, such as physical therapists (PTs), occupational therapists (OTs), and certified hand therapists (CHTs), have unique roles on an interprofessional team to improve patient engagement in desired activities. Furthermore, these professionals, through collaboration with biomechanical engineers, have an opportunity to provide their patients with 3D printed prosthetics explicitly designed to meet individual task needs. Utilizing innovative 3D printing technology as a viable alternative to fabricate a functional prosthetic is fast becoming a reality for therapists as they work with and advocate for those with limb loss.2,10 Therapists are highly trained in providing various types of adaptive technology, including 3D printed prosthetics. Because the commercially available technology is continually evolving, therapists can find it challenging to keep up on the changing trends. Biomedical engineers have a primary role in keeping up with and have a solid understanding of the changing trends in technology, and this opens the door for interdisciplinary collaboration. Engineers are skilled in understanding and identifying equipment, and therapists are trained in implementing it for task-specific needs. ${ }^{11}$

This research explored the capabilities of utilizing 3D computer design software for prosthetic fabrication, specifically in customizing a design to meet individualized client needs. The purpose of this research is to explore the ease of utilizing task-specific design in computer-aided, open-source 3D printed design software.

The research questions for this study are the following:

1. What is the ease of extracting task-specific information from client assessments to guide the individualized design of a functional digit prosthetic?

2. Can client-specific task information be accurately utilized by the interdisciplinary team to create an open-source 3D printed design?

\section{METHODOLOGY}

\section{Study Design and Procedures}

A case study design with an $n$ of 2 was utilized. Individuals with digit amputations were observed with the aim of understanding the subsequent impact on their desired activities. This study used a mixed-methods embedded design. ${ }^{12} \mathrm{An}$ embedded design utilizes qualitative and quantitative data to effectively address the research questions. The primary method of data used was qualitative. Quantitative data supplemented the study to answer the research questions. The use of patient-reported outcome measures, semi-structured interviews, and a variety of objective assessments was included. Appropriate use of various data collection techniques allows for the increased rigor of findings and expands the scope of the research. ${ }^{13,14}$ The research continuum was broken down into two phases: Phase 1, the clinical phase, and Phase 2, the interpretive phase. Phase 1 included all communications with participants and the completion of the prosthetic design. Phase 2 included the review of all tasks involved in Phase 1 to address the research questions through the identification of prominent themes. 


\section{Ethical Considerations}

Institutional Review Board (IRB) approval was obtained from the research team's institution before conducting the study. Informed consent included photo and video recording to aid in the analyses. Researchers from both disciplines recorded detailed field notes throughout the research process to ensure results yielded from this study accurately represent the methods completed.

\section{Field Notes}

Engineering and occupational therapy (OT) disciplines documented detailed, narrative-style field notes throughout Phase 1 of the research continuum and the duration of each research team meeting or meeting with the participants. Members of both research disciplines documented field notes through paper and electronic mediums. Additionally, research disciplines shared field notes with all other research team members through an online platform. Team members discussed relevant field notes before making participant-oriented decisions, such as assessment choice and design details. Field notes documented the following: participant assessment results, clinical decision making, design options and component parts, and other relevant information regarding encounters with participants or team meetings. During Phase 2 of this research, field notes were compiled and reviewed collaboratively to extract significant themes addressing the research questions. These were culminated through the evaluation and interpretation of field notes to address the research questions.

\section{Research Participants}

Participants were identified through convenience sampling known to the OT members of the research team. The inclusion criteria captured those individuals who: are over the age of 18 , have had at least one finger amputation, and are not currently receiving health care interventions for their impaired body structure.

Participant 1 is an older male with no self-disclosed comorbid conditions that impacted this research. However, he has limited experience with digit prosthetic use through participation in a pilot research project but was not issued a prosthesis. He sustained partial amputations of his index, middle, and ring fingers on his dominant right hand during a woodchipper accident 28 years ago. The distal interphalangeal (DIP) joints of all three fingers were amputated (Figure 1). He experienced contractures in the remaining residual digits. He experienced phantom pain in the amputated digits post-injury but has not experienced pain in the past several years other than sensitivity when he bumps his residual digits into firm objects.

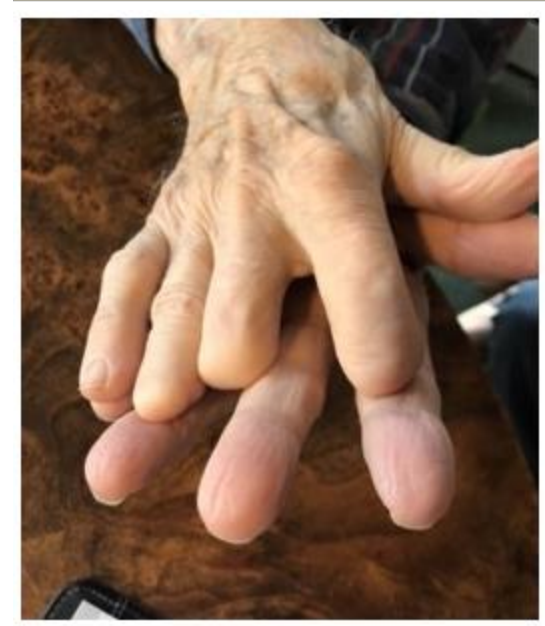

Figure 1. Participant 1 right hand

Participant 2 is a 76-year-old female with no self-disclosed comorbid conditions that impacted the research and has no previous experience with finger prosthetics. She was previously employed as a social worker. She experienced an amputation of her index finger on her nondominant left hand when she was 21 years old while utilizing a circular table saw. The accident resulted in an amputation at the proximal interphalangeal (PIP) joint (Figure 2). Presently, she denies pain, numbness, and tingling in her left hand. However, she does experience arthritis primarily in her dominant right hand and wrist. 


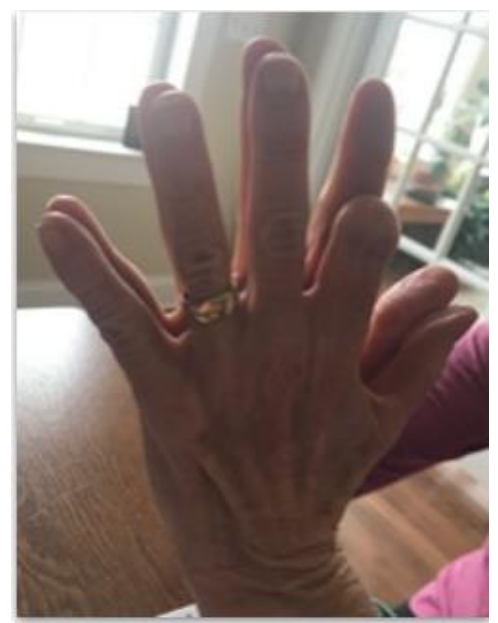

Figure 2. Participant 2 left hand

\section{Assessments}

The objective assessments conducted with both participants were: the MacHANd Performance Assessment (MPA), and Jamar dynamometry and B\&L pinch gauge assessments. Dynamometry data was collected for both hands. Both participants engaged in three trials on handle settings 2, 3, and 4, with an average score calculated for their affected and non-affected hands. Three trials assessed pad-to-pad and tip-to-tip pinches, with an average score calculated for both types of pinches. Participant 1's left ring finger and right residual ring digit were evaluated. Participant 2's right index finger and left residual index digit were assessed. The MPA was administered, though Task 16, a 9-hole peg test, was omitted for both participants. All tasks were video recorded and observed while being scored in real-time. At a later time, all researchers observed the video recordings and reached a consensus regarding the participants' scores. Additionally, the Box and Blocks Test (BBT) was completed with Participant 2; the researchers elected not to complete it with Participant 1 because the BBT only assesses prehension of the index finger and thumb, which was not evaluated for Participant 1.

Both participants engaged in a subjective semi-structured interview about their goals, expectations, and desired areas of functional improvement. The Canadian Occupational Performance Measure (COPM) was used to guide the interviews, using questions that applied to the participants, but disregarding the scoring sections of the measure. One member administered the COPM, while a second recorded detailed field notes of the participants' responses. Interviews were recorded both electronically and hard copy. All responses were analyzed during Phase 2. Another subjective assessment, the Hand Assessment Tool (HAT), was also administered to Participant 2.

All of these assessments can be used for populations experiencing impaired body structures and are appropriate for participants with impairments to the wrist and hand axis.

\section{Objective Outcome Measures}

The MPA is an outcome measure used to assess a person's impaired hand functioning while completing occupation-based tasks. 15 Examples of tasks include simulated drinking and eating, pouring water into a jug and a pan, lifting objects onto a shelf, picking up items commonly found in a home, such as a dime or buttons, and a timed writing task. ${ }^{15}$ It assesses the International Classification of Functioning (ICF) domains of body function and activity limitations. A score of 100 indicates maximum functioning. Existing literature supports the psychometric properties of the MPA. The MPA has good interrater reliability, excellent test-retest reliability, and evidence for validity, as it confirmed three validation hypotheses. ${ }^{15}$

The BBT is an outcome measure used to assess unilateral gross manual dexterity. During the assessment, the participant moves one-inch blocks from one side of a box divided with a partition to the other side. The participant moves only one block at a time, and their score is dependent on how many blocks they can transfer in one minute. ${ }^{16}$ It assesses the ICF domain of body function. The BBT has excellent test-retest reliability and excellent inter-rater reliability. ${ }^{17}$ In terms of validity, there is no golden standard with which to compare the BBT. However, there is preliminary evidence supporting predictive and construct validity. ${ }^{17}$ 


\section{Subjective Outcome Measures}

The HAT is a subjective assessment tool that is self-administered. It assesses activity limitations experienced by individuals with hand and wrist injuries. ${ }^{18}$ It has preliminary evidence for solid validity and reliability. ${ }^{18} \mathrm{~A}$ score of zero indicates no dysfunction in the range of domains explored by the questionnaire, with higher scores reflecting a greater level of dysfunction.

The COPM is a subjective measure used to assess the ICF domain of participation through meaningful activities. ${ }^{19}$ It aids individuals in determining what areas of their life they are experiencing participation restrictions and rates their daily activities according to importance and satisfaction in completing those activities. ${ }^{19}$ It provides the basis for creating goals for treatment based on the area(s) of deficit identified by the individual during a semi-structured interview. First, the individual identifies problematic areas of their life based on various occupations in self-care, productivity, and leisure. Then, the client rates each occupation on a scale of one to ten in terms of importance. The administrator then takes the top five problem areas and asks the individual to rate their satisfaction with their performance of each problem area, again on a scale of one to ten, with ten being good performance and high satisfaction. Finally, at the end of the intervention, the administrator reassesses the individual to determine if there are any changes in the satisfaction and performance scores of the five problem areas. ${ }^{19}$

\section{Grip and Pinch Strength}

The JAMAR dynamometer adjusts to five different handle settings. ${ }^{20}$ The participant squeezes the dynamometer with their maximum strength, and the administrator records the force of their grip in pounds or kilograms. According to the National Institute for Health Research, an appropriate assessment using a JAMAR dynamometer involves three trials of each hand.21The B\&L pinch gauge measures pinch strength in both pounds and kilograms. ${ }^{22}$ The participant holds the gauge between their thumb and finger, and the administrator assesses the participant's tip, key, and palmar pinch. According to the OT Assessment Guide, an appropriate pinch gauge assessment includes three trials with an average of the three trials calculated for each pinch type assessed. ${ }^{23}$

Both dynamometers and pinch gauges have evidence for reliability and validity. ${ }^{24,25}$ Evidence that dynamometry is a valid and reliable measure of hand and grip strength is confirmed by several sources. ${ }^{24} \mathrm{~A}$ dynamometer has strong inter-rater reliability, and a pinch gauge has good test-retest reliability. ${ }^{25}$ pp. 1,3

\section{Prosthetic Design}

The Knick Prosthetic Finger v3.5.5 is an open-source design for a prosthetic digit, available on Thingiverse, an online platform for sharing 3D printed designs. ${ }^{26}$ The prosthetic files utilized include guidance for designing, fabricating, and assembling the device. This design was used with the addition of a wrist strap design to act as an attachment point for the device.

\section{Measurements}

Specific measurements of both participants' hands and residual digits were taken to create a computer-aided design (CAD) of the digit prosthetic, a wrist strap, and a connecting wire from the strap to the digit prosthetic. The measurements required are outlined in the Knick v3.5.5 design available on Thingiverse. ${ }^{26}$ The Knick v3.5.5 design is one of the designs available on Thingiverse and was chosen due to familiarity and ease of access. The measurements for Participant 1 included right wrist and palm circumference, the height of the dorsal side of the right hand, length and width of all left and right digits, and individual phalanx measurements of the left, non-affected ring finger. Measurements for Participant 2 included left wrist and palm circumference, the height of the dorsal side of the left hand, length and width of all left and right digits, and individual phalanx measurements of the right, non-affected index finger.

The digit measurements were taken because they are required to create a CAD drawing of the digit prosthetic. The wrist, palm, and dorsal measurements were taken to create a wrist strap and wire tendon mechanism and to adjust the dimensions on the finger prosthetic. The wrist strap attaches to the participant around the wrist, just proximal to the radial and ulnar styloid processes, to stabilize the prosthetic onto the extremity. The wire mechanism attaches from the wrist strap to the prosthetic base on the dorsal side of the hand and imitates a natural tendon network.

Linear measurements were taken using an electronic caliper measured to the nearest hundredth of a millimeter, and circumference measurements were taken using a string method. The measurement process entailed wrapping a string around the finger and then measuring the string's length using the caliper. This method allowed for maximized patient comfort and accurate measurements of the hand regarding prosthetic length and ratio to the remaining anatomy. 


\section{Computer-Aided Design}

After gathering measurements, the data was input into a computer program to create CAD drawings (Figures 3 and 4 ).

Measurements needed to design the digit itself were input into OpenSCAD because this program contains the open-source code for the digit. OpenSCAD is a software application that allows for uploading a 3D design and scaling to meet individualized sizes. OpenSCAD also allows for the creation of a computational analysis, which determines if the device is capable of supporting loads of daily tasks.

The XYZ 3D printer can fabricate individual prosthetic designs using multiple types of filament. ${ }^{10}$ This printer requires that all device component dimensions are greater than $1 / 16$ th of an inch, to remain stable while printing. For the $3 \mathrm{D}$ printer to interpret the CAD drawings, they must be converted into stereolithography (STL) files, because an STL is the only file type the printer would read. Those STL files should then be sent to the printer, and the dimensions would be verified to ensure that they will be customized to the participant.

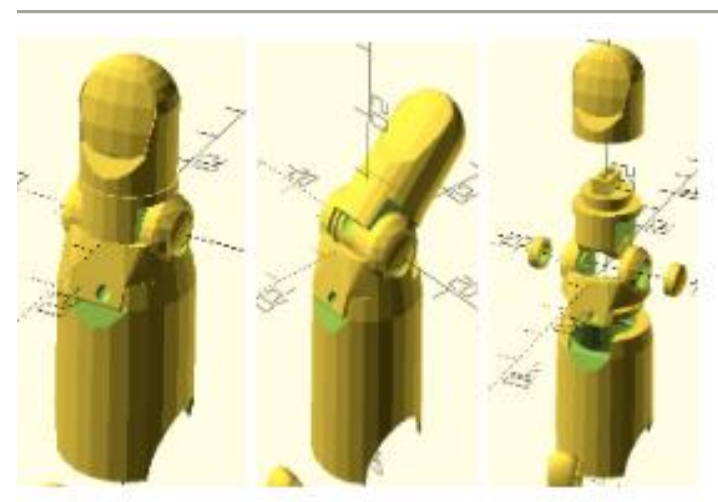

Figure 3. Data input to create $C A D$ drawings

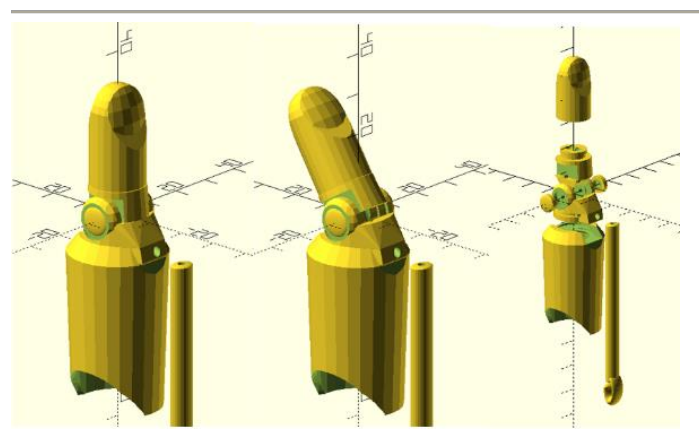

Figure 4. Data input to create CAD drawings

\section{RESULTS}

Phase 1

\section{Participant 1: Objective Assessments}

The MPA assessment, in which a score of 100 indicates maximum functioning, was administered to Participant 1. He scored a 78/95, and his specific results are outlined in Table 1. Using handle setting 2 of the Jamar dynamometer, Participant 1 recorded 63.93 pounds of force with the right, dominant, affected hand, compared to 60 pounds of force with the left, nondominant, nonaffected hand. He recorded 7.34 pounds of force with his right pad-to-pad pinch, compared to 6.00 pounds with his left.

\section{Participant 1: Subjective Assessments}

While conducting the COPM, Participant 1 identified functional limitations in the following areas: gardening, making his bed, buttoning his shirt, putting on socks, and assisting his wife in self-care activities. Recently, he had to shift his daily roles to providing care for his wife. He stated: "being a caregiver is a full-time job." Being a caregiver to his wife includes all aspects of household management and meal preparation. He also stated that he "[doesn't] have much time leftover" for leisure activities because of this new role. 


\section{Participant 2: Objective Assessments}

The MPA assessment was administered to Participant 2, where she scored a 69/95. Her detailed results are outlined in Table 1. Using handle setting 2 of the Jamar dynamometer, Participant 2 recorded 38.21 pounds of force with the left nondominant, affected hand, compared to 33.80 pounds of force with the right, dominant, non-affected hand. She recorded 6.98 pounds of force with her left pad-to-pad pinch, compared to 9.19 pounds with her right. Participant 2 completed the BBT with her right, dominant, nonaffected hand, and left, nondominant, affected hand. She moved 54 blocks with her right hand, and 41 blocks with her left hand.

\section{Participant 2: Subjective Assessments}

As the COPM was conducted with Participant 2, she expressed that her amputation does not significantly impact her. However, she did identify several areas in which a prosthetic device may improve functional performance. These areas included: typing, holding onto her dog's leash, picking up objects from smooth surfaces, turning on lamps, and pointing. She further expressed that participation in various leisure and volunteer activities is important to her, stating, "I get out a lot." Recently, she experienced seizures, which impacted her ability to drive. She currently relies on her husband and friends to transport her to her various activities. Participant 2 completed the HAT through self-report, with some clarification of the meaning of certain items. She completed the HAT with a score of $5.36 / 100$, indicating that she experiences a relatively low level of dysfunction in the range of domains explored by the questionnaire.

Table 1: MacHANd Assessment

\begin{tabular}{|c|c|c|c|c|c|}
\hline \multicolumn{3}{|c|}{ Participant 1} & \multicolumn{3}{|c|}{ Participant 2} \\
\hline Task & Score & $\begin{array}{l}\text { Design } \\
\text { Implications }\end{array}$ & Task & Score & $\begin{array}{l}\text { Design } \\
\text { Implications }\end{array}$ \\
\hline 7. Slates & 2 & $\begin{array}{l}\text { Difficulty } \\
\text { completing } \\
\text { task due to } \\
\text { decreased } \\
\text { expansion } \\
\text { and spanning }\end{array}$ & 5. Circles & 2 & $\begin{array}{l}\text { Difficulty } \\
\text { completing } \\
\text { task due to } \\
\text { limited index } \\
\text { finger dexterity }\end{array}$ \\
\hline 17. Jugs & 4 & $\begin{array}{l}\text { Difficulty } \\
\text { completing } \\
\text { task due to } \\
\text { decreased } \\
\text { grip strength }\end{array}$ & 7. Slates & 3 & $\begin{array}{l}\text { Difficulty } \\
\text { completing } \\
\text { task due to } \\
\text { decreased } \\
\text { expansion. } \\
\text { First slate: "I } \\
\text { can't even } \\
\text { reach it" (with } \\
\text { index) }\end{array}$ \\
\hline 19. Cans & 4 & $\begin{array}{l}\text { Difficulty } \\
\text { completing } \\
\text { task due to } \\
\text { decreased } \\
\text { grip strength }\end{array}$ & 15. Nut and Bolt & 2 & $\begin{array}{l}\text { Difficulty } \\
\text { completing } \\
\text { task due to } \\
\text { limited index } \\
\text { finger dexterity }\end{array}$ \\
\hline
\end{tabular}

\section{Phase 2}

\section{Prosthetic Design Development}

Developing a digit prosthetic using an open-source design was a smooth and quick process. This process first required obtaining necessary measurements from the participants. Once measurements were acquired, they were input into the open-source design software, which were then converted into STL files to ensure the printer could read and interpret the information. The Knick v3.5.5 manual outlined each step of this process, and the software programming was user-friendly. ${ }^{25}$ In terms of adapting the prosthetic design, the semi-structured interview was utilized to aid in consideration of the force load directions that would be necessary to complete the identified tasks. Additionally, a design was selected that was made of durable material that could withstand various task loads. 


\section{Ease of Extracting Task-Specific Information}

The following domains were identified to answer the first research question: appropriate assessment utilization, time management, and participant responsiveness.

\section{Appropriate Assessment Utilization}

First, the research required objective and subjective data to address participation restrictions and activity limitations identified by the participants. Thus, assessment tools were chosen that addressed both data types. For example, the semi-structured characteristics of the COPM allowed for the identification of task-specific information, including roles and impairments experienced by the participant, fulfilling the need for subjective data. Next, the assessments chosen for this research were selected based on their ability to address the structure and function of the digits and the hand as a whole. The BBT, MPA, HAT, Jamar dynamometry, and B\&L pinch gauge assessments were chosen as a result. Finally, these assessments were chosen based on their ease of administration and total administration time, equating to less than one hour to prevent participant fatigue.

\section{Time Management}

This domain addresses the experience of coordination and planning to create a streamlined schedule of events during participant meetings. During the research process, both participants had flexible schedules that allowed for ease of arranging data collection meetings, while also ensuring that at least two OT and two engineering researchers could attend each session with the participants. The presence of both disciplines allowed for maximized time efficiency and a high level of interdisciplinary collaboration that was vital in creating a functional design.

Both participants were always amicable and compliant in meeting for hour-long sessions. The research team worked together well to manage the sequence of events of all meetings to maintain the hour time cap. For example, after deciding a time and date to meet with a participant and establishing which team members would be present, the team communicated to determine which members would complete what tasks and in what order the tasks would be completed. All members were flexible in establishing a schedule for each meeting; this led to substantial preparedness that made the data collection process simple and straightforward.

\section{Participant Responsiveness}

The ease and effectiveness of all interactions between the researchers and the two participants of this study were addressed within the domain of participant responsiveness. Generally speaking, the participants were highly involved throughout the process of Phase 1. Initial interactions with each participant illustrated intrinsic and extrinsic motivation for participation in this study, which provided a strong foundation for success. For example, when asked what his goals were for engaging in this study, Participant 1 responded by saying, "I want you to get the information you need to do your research." Participant 2 asked the researchers to provide her with a copy of her assessment results and videos because they were "so fascinating." At the time of this study, both participants had already made adaptations to daily tasks or their environment to optimize functioning. However, both participants quickly identified specific tasks that are challenging to complete due to their amputation. This is a vital component to the creation of an individualized, task-specific prosthetic design because it allows the researchers to (1) design a prosthetic that the participant is likely to wear, (2) design a prosthetic that the participant is likely to identify as useful, and (3) orient functional assessments around the skills needed to complete the designated task(s). Overall, both participants were receptive to the research process and prosthetic intervention, despite not using a prosthetic device in their daily lives. Moreover, the participants were understanding and tolerant of the assessment procedures. The guided interviews were direct, generating pertinent information over a relatively short time; initial semi-structured interviews with each participant yielded critical, task-specific knowledge in less than one hour. Minimal clarification was required to obtain a direct answer to any interview questions.

One complication identified by the researchers in terms of participant responsiveness was maintaining sufficient, ongoing communication with Participant 1 . The researchers' primary communication methods with the participants were phone calls, emails, and in-person meetings. Participant 1, however, does not have an email address, which limited correspondence to phone calls. This presented some challenges, as the researchers did not always make contact with Participant 1 and were required to leave him voice messages via phone. These communication barriers resulted in a longer prosthetic design process from start to finish.

\section{Developing a 3D Design}

The following domains were identified to answer the second research question: clinical reasoning, common language, and available resources. 


\section{Clinical Reasoning}

The domain of clinical reasoning is utilized to address the second research question. Throughout each phase of the research process, there were different elements in which clinical reasoning skills were used to establish a computer-aided 3D prosthetic design. For example, the researchers decided to keep the sessions no more than an hour for two reasons: (1) consideration of the participants' ages and concern for fatigue, and (2) to simulate a typical rehabilitation session. In Phase 1, clinical reasoning was exemplified by gathering measurements of each participant's residual digits and their opposing unaffected digits to create a design in likeness to their prior anatomy. However, clinical reasoning was particularly evident while designing Participant 2's prosthetic. Her amputation is at the PIP joint articulation. Simulating both interphalangeal joints would have caused extensive length, taking away from the prosthetic's function and anthropomorphic quality. Therefore, her design had only one interphalangeal joint, and it approximated normal finger length. When taking measurements, clinical reasoning was demonstrated by finding a balance between designing a formfitting yet comfortable prosthetic. This was achieved by not pulling the caliper tool too tight on each digit to collect a correct measurement, while also ensuring the prosthetic design would create a snug and comfortable fit on the chosen residual digit. When discussing which materials would be most beneficial to create a functional 3D digit prosthetic design, clinical reasoning was utilized to establish the need for the use of soft and hard filaments.

According to field notes from engineering members of the team, the XYZ 3D printer was chosen due to its advanced printing capabilities. This printer can print with multiple types of filament. Each filament type has different material properties. Personal experience exemplified in the engineering team's field notes indicated that to create a functional Knick v3.5.5 digit prosthetic, a flexible TPU filament and hard PLA filament is required. The knuckle pieces of the prosthetic must be made of hard PLA filament, so they can hold together and bend properly without deforming while bearing various task loads. The socket, tip cover, and hinge covers were designed using the flexible TPU filament, so a printed model could conform to the residual digit and knuckle pieces without discomfort or breaking.

\section{Common Language}

The ICF categorizes human functioning on a global scale. ${ }^{27}$ This framework considers an individual's health conditions and how these conditions can influence participation in activities. ${ }^{28}$ The ICF describes dysfunction as it occurs in any of the following domains: impairments of body structure and function, activity limitations, and participation restrictions. ${ }^{28}$ Due to the interdisciplinary approach required by the prosthetic care process, practitioners in many healthcare disciplines must understand the scope of all disciplines involved to address the clients' individualized health needs effectively. The ICF allows for the utilization of an interdisciplinary language while discussing individuals' health and functioning. ${ }^{28}$

One minor obstacle encountered during collaboration was the use of a common language between both disciplines. Communication proved to be a challenge within the research team due to half of the members not working within a medical field. The OT members of the team required frequent clarification during conversations to ensure they understood the engineering jargon related to computer engineering. Additionally, the engineering members required explanations regarding the chosen assessments, why they were chosen, what the results were, and what they meant. Therefore, triangulation was crucial to ensure all pieces of information were understood correctly.

\section{Available Resources}

This domain discusses the resources, both online and in-person, that the research team had access to facilitate the research process. A significant advantage identified in this research was access to online software, Thingiverse and OpenSCAD, through the research team's institution. Access to these resources made the CAD drawing and prosthetic design process uncomplicated, as the team already had these resources readily available for use. Additionally, the ease of designing the prosthetic is attributed to easy access to the Knick finger open-source design on Thingiverse.

Inputting the measurements into the software to create CAD drawings also was straightforward. Overall, the process was user friendly and brief. The streamlined and simple process of exporting the CAD drawings and converting them to STL files took only minutes. The design of one digit can easily be modified to another digit, which was important for the purpose of this research since the designs were developed for Participant 1's ring finger and Participant 2's index finger. Additionally, the design was oriented within the computer software so that the material fibers would be perpendicular to the weight of the task loads. This allows the device to bear the most weight while completing various activities. Without these capabilities, the device would not be designed for optimal function. 


\section{DISCUSSION}

\section{Importance of Task-Specific Selection in Adaptation}

It is essential to have a structured way to fully identify task needs and wearing times to encompass the design's task-specific nature. In this research, the chosen objective and subjective assessments were able to identify several desired tasks chosen by both participants. After identifying task needs, exploring a variety of customization options for the prosthetic device to meet these needs was required. Through assessing Participant 1's results, his recent role change to a caregiver was revealed. A prosthetic design for his residual ring digit could be useful while completing his caregiving tasks. Household management tasks, such as preparing meals or cleaning, involve strength and expansion of the fingers. This is maximized by the ring finger, since strength and spanning come from the ulnar side of the hand. For Participant 2, assessment results found that her amputation hindered her typing and picking up and grasping objects, such as her dog's leash. Designing a prosthetic to assist her in completing tasks with fine motor control, like picking up small objects, would be most useful. In her situation, the prosthetic device would be most helpful if worn while completing occupations requiring these identified tasks, such as attempting to pick up her dog's leash. While Participant 2 completed the HAT, the only area of difficulty she reported encountering was decreased body image. Although the Knick prosthetic finger does not offer advanced aesthetic customization, the color of the material could be an option to meet aesthetic needs. Overall, implementing structured assessment techniques with the participants facilitated proper identification of desired occupations. Thus, customizing the prosthetics to meet these task needs is likely to result in maximized prosthetic adherence, increased task performance, and participant satisfaction. Effective collaboration between OTs and engineers while utilizing 3D printing technology allows for this high level of custom and individualized prosthetic design.

\section{Importance of Interprofessional Collaboration}

Collaboration between OTs and engineers has become an integral part of interprofessional relations due to recent advancements in technology and the role technology plays in healthcare. Both OTs and engineers have the same desired outcome concerning patient care: to assist individuals in participating in their daily roles. ${ }^{7}$ OTs and engineers work hand-in-hand to determine the technology that will best assist an individual in partaking in a task, and how to design and develop the needed device. The OT members of the team were well prepared to identify desired tasks for which the participants could use their prosthetic devices, and the engineering members of the team were experts in developing a design that would be able to function correctly during said tasks. The engineering members were able to analyze the various task loads the prosthetic would need to endure, and choose a prosthetic design that would support those task loads.

Representatives from both disciplines must be heavily involved in all research processes, regardless of the discipline's scope. This would allow all research members to comprehend the process in a manner most advantageous for the development of the devices. The use of a common language, such as the ICF, would be an appropriate supplement to the strategies mentioned above. ${ }^{6}$ The ICF is written in such a way that members from all disciplines would be able to understand its language, which would potentially reduce confusion and miscommunication.

\section{Limitations}

Throughout the research process, one limitation encountered with the methodology was the use of convenience sampling within a case study design. Both participants were chosen as a result of personal connections and may have contributed to researcher bias during the evaluations. To comply with the inclusion criteria, neither participant was receiving skilled medical services concerning their amputations at the time of assessment. Additionally, each participant had acquired amputations many years prior to this research and had adapted to complete their desired roles and activities. The participants may have been able to identify further task limitations had they incurred their amputation more recently. It may have been beneficial to consider comparing those with more recent amputations to those who have adapted with their digit amputations over a multitude of years.

\section{Implications for Future Research}

Future research utilizing these findings will be needed to address the efficacy of designing and fabricating and implementing customized single 3D digit prosthetics for individuals regarding their participation in desired activities and roles.

Future researchers should fabricate a 3D printed prosthetic using CAD drawings based on the Knick v3.5.5 finger design to meet clients' specific task needs. Additionally, constant observation of the 3D printing process to address any issues that may arise while printing is suggested. The methodology should be an experimental design to determine the ease of fabricating and adapting a 3D printed digit prosthetic to a client's needs and to determine the efficacy of implementing an individualized 3D printed digit prosthetic on engagement in desired tasks. Possible prosthetic design improvements could be being mindful of skin integrity, creating a functional wearing schedule, and potentially adding external modifications for increased gripping and prehension abilities. Other considerations include adding a neoprene sleeve to protect the hand and wrist's skin integrity and to anchor points of attachment 
at the most proximal joint of the affected digit and the wrist. Also, a neoprene sleeve may be considered to protect the attachment network from friction due to use over time.

\section{CONCLUSION}

Impairments in the upper extremity, including amputations, can impact daily functioning; further developments in biological technology are necessary to meet these needs. ${ }^{2}$ During this research endeavor, both participants were able to identify tasks that could benefit from the design of a customized 3D printed finger prosthetic. The use of qualitative and quantitative data provided a straightforward means of creating a design. The process of developing a customized 3D design is highly dependent on identifying meaningful tasks and collaboration between OTs and engineers. Utilizing the Knick v3.5.5 prosthetic design available on Thingiverse was a quick and straightforward process, allowing for the application of the participant's identified task needs and customized wear. Future research would be beneficial to address limitations in the current study and solidify the functional benefits of fabricating and implementing a task-specific device for individuals with digit amputations.

\section{ACKNOWLEDGEMENTS}

Significant credit goes to Dr. Kurt DeGeode and four students: Elle Shatto, Damon Edwards, Travis Wilson, and Robert Pavlik, who were completing their senior project in engineering. Particular recognition goes to Dr. Terri Dennehy for her faculty oversight. Finally, thank you to Mark Gatti for fabricating the BBT assessment tool's box and partition.

\section{REFERENCE LIST}

1. How do hands work? IQWiG. 2010. https://www.ncbi.nlm.nih.gov/books/NBK279362/. Published August 31, 2010. Updated July 26, 2018. Accessed May 2, 2020.

2. Young K, Pierce JE, Zuniga JM. Assessment of body-powered 3D printed partial finger prostheses: a case study. J $3 D$ Print Med. 2019;5(7):1-8. doi:10.1186/s41205-019-0044-0. Published May 2, 2019. Accessed May 2, 2020. [PMID 31049828]

3. Manero A, Smith P, Sparkman J, Dombrowski M, Courbin D, Kester A, Womack I, Chi A. Implementation of 3D printing technology in the field of prosthetics: past, present, and future. Int J Environ Res Public Health. 2019;16(9):1641. doi:10.3390/ijerph16091641. Published May 10, 2019. Accessed May 2, 2020. [PMID 31083479]

4. Ootes D, Lambers KT, Ring DC. The epidemiology of upper extremity injuries presenting to the emergency department in the united states. Hand (N Y). 2011;7(1):18-22.doi:10.1007/s11552-011-9383-z. Published December 14, 2011. Accessed May 2, 2020. [PMID 23449400]

5. Jamayet NB, Pokpong A, Aiam MK. Finger prosthesis: a case report. Int Med J. 2014;21(4):428-429. http://search.ebscohost.com/login.aspx?direct=true\&db=ccm\&AN=107828684\&site=ehost-live. Accessed May 2, 2020.

6. Jang $\mathrm{CH}$, Yang $\mathrm{HS}$, Yang $\mathrm{HE}$, et al. A survey on activities of daily living and occupations of upper extremity amputees. Ann Rehabil Med. 2011;35(6):907-921. doi:10.5535/arm.2011.35.6.907. Accessed August 11, 2020.

7. Sansoni S, Wodehouse A, McFayden A, Buis A. The aesthetic appeal of prosthetic limbs and the uncanny valley: the role of personal characteristics in attraction. International Journal of Design. 2015;6(9):67-81. http://www.ijdesign.org/index.php/IJDesign/article/view/1450/676. Published April 30, 2015. Accessed May 2, 2020.

8. Biddiss E, Chau T. Upper limb prosthesis use and abandonment: a survey of the last 25 years. Prosthetics Orthot Int. 2007;31(3):236-57. doi:10.1080/03093640600994581. Accessed August 11, 2020.

9. Østlie K, Lesjø IM, Franklin RJ, Garfelt B, Skeldal OH, Magnus P. Prosthesis use in adult acquired major upper-limb amputees: patterns of wear, prosthetic skills and the actual use of prostheses in activities of daily life. Disability and Rehabilitation: Assistive Technology. 2012;7(6):479-493. doi:10.3109/17483107.2011.653296. Accessed August 11, 2020.

10. Alvial P, Bravo G, Bustos MP, Moreno G, Alfaro R, Cancino R, Zagal JC. Quantitative functional evaluation of a 3Dprinted silicone-embedded prosthesis for partial hand amputation: a case report. J Hand Ther. 2017;31(1):129136.doi:10.1016/j.jht.2017.10.001. Published December 1, 2017. Accessed May 2, 2020. [PMID 29196160]

11. Mihailidis A, Miller Polgar J. Occupational therapy and engineering: being better together. Can J Occup Ther. 2016;83(2):68-71. doi:10.1177/0008417416638842. Published March 29, 2016. Accessed May 2, 2020. [PMID 27026718] 
12. Choosing a mixed methods design. In Creswell JW, and Plano Clark VL, eds. Designing and Conducting Mixed Methods Research. SAGE Publications, Inc.; 2011. Available at: https://www.sagepub.com/sites/defaultffiles/upmbinaries/10982 Chapter 4.pdf. Accessed May 2, 2020.

13. Harrell M, Bradley M. Data collection methods: semi-structured interviews and focus groups. Santa Monica: National Research Institute; 2009. Available at: https://www.rand.org/content/dam/rand/pubs/technical_reports/2009/RAND_TR718.pdf. Accessed May 2, 2020.

14. Sandelowski M. Combining qualitative and quantitative sampling, data collection, and analysis techniques in mixedmethod studies. Res Nurs Health. 2000;23(3):246-255. doi:10.1002/1098-240x(200006)23:3<246::aid-nur9>3.0.co;2-h. Published June 22, 2000. Accessed May 2, 2020. [PMID 10871540]

15. Packman TL, Landman EC, Muhic A, Hebert AJ, Ball PD. Measurement properties of the MacHAND Performace Assessment: a pilot study. Can J Occup Ther. 2012;79(5):303-308. doi:/10.2182/cjot.2011.79.5.6. Published December 2012. [PMID 23539775]

16. Amini D, Motor and Praxis Assessments. In: Asher IE, Asher's Occupational Therapy Assessment Tools: An Annotated Index. $4^{\text {th }}$ ed. American Occupational Therapy Association, Inc; 2014.

17. Box and Blocks Test (BBT): psychometric properties. Strokengine.ca. https://www.strokengine.ca/en/psycho/bbt_psychol. Published 2020. Accessed August 11, 2020.

18. Naidu SH, Panchik D, Chinchilli VM. Devemopment and validation of the hand assessment tool. J Hand Ther. 2009;22(3):250-257. doi:10.1016/j.jt.2008.11.003. Published September, 2009. [PMID 19278829]

19. About the COPM. TheCOPM.ca. http://www.thecopm.ca/about/. Published 2020. Accessed August 11, 2020.

20. Patterson Medical. JAMAR Hydraulic Hand Dynamometer Owner's Manual. Performancehealth.com. https://www.performancehealth.com/amfile/file/download/file/2329/product/27106/. Accessed August 11, 2020.

21. National Institute for Health Research. Procedure for measuring grip strength using the JAMAR dynamometer. Uhs.uk. https://www.uhs.nhs.uk/Media/Southampton-Clinical-Research/Procedures/BRCProcedures/Procedure-for-measuringgripstrength-using-the-JAMAR-dynamometer.pdf. Updated May 2014. Accessed August 11, 2020.

22. Pinch gauge instructions. Baselineproducts.net. https://www.3bscientific.com/product-manual/W50176.pdf.

23. Mead A, Gampe C, Soergel L, Stiltenpole K. Occupational therapy assessment guide: pinch guide. Otassessments.wordpress.com. https://otassessments.wordpress.com/dynamometry/pinchstrength/\#: :text=Have\%20client\%20perform\%20one\%20of,average\%20of\%20the\%20three\%20trials. Accessed August 11, 2020.

24. Stark T, Walker B, Phillips JK, Fejer R, Beck R. Hand-held dynamometry correlation with the gold standard isokinetic dynamometry: a systematic review. PM R. 2011;3(5):472-479. doi:/10.1016/j.pmrj.2010.10.025. Published May, 2011. [PMID 21570036]

25. McCaffrey L, LeFebvre R. Dynamometer (grip) and pinch gauge. Published July, 1999. Accessed August 11, 2020.

26. Digital Designs for Physical Objects. https://www.thingiverse.com/about/. Updated 2020. Accessed May 2, 2020.

27. World Health Organization. About WHO. https://www. who.int/about. Updated 2020. Accessed May 2, 2020.

28. World Health Organization. Toward a common language for functioning, disability and health: ICF. Geneva: World Health Organization; 2002:1-22. Available at: https://www.who.int/classifications/icf/icfbeginnersguide.pdf. Accessed May 2, 2020. 